\title{
Implementing Efficiency Measures of Forms Enhancing Employees' Competencies by Middle-Sized Companies Operating on the Polish Market—Research Results Based on the Case Study Method
}

\author{
Joanna Żukowska, Mikołaj Pindelski \\ Warsaw School of Economics, Warsaw, Poland
}

\begin{abstract}
The analysis of literature indicates that there are gaps in both science and practice related to the efficiency measures of forms enhancing employees' competencies. Performance indicators can be seen as a part of the evaluation of training courses carried out immediately after their completion. However, consistent and comprehensive research on the effectiveness of various forms increasing the competence and development of employees is rarely observed. The purpose of this article is to present the results of a research using the case study method.
\end{abstract}

Keywords: competencies, development, efficiency measure, employee, training

\section{Introduction}

The analysis of literature indicates that there are gaps in both science and practice related to the efficiency measures of forms enhancing employees' competencies. Performance indicators can be seen as a part of the evaluation of training courses carried out immediately after their completion. However, consistent and comprehensive research on the effectiveness of various forms increasing the competence and development of employees is rarely observed. The purpose of this article is to present the results of a research using the case study method.

The analysis of literature shows that the concept of enhancing employees' competencies and their development is often identified. Naturally, looking closer at the concepts, we can state that the concept of development is broader than the term "increasing of competence." Interestingly enough, we can observe great interest in the topic of competence in the 1990s and 2000s, but after 2007, there is a clear decrease in the incidence of publications on this topic. This may be a sign that, again, there is a gap in the study, which can be explored and filled in.

\section{Methods}

The methodology of an empirical study is based on in-depth interviews with the research sample characteristics. Forty in-depth interviews were carried out in the second part of the empirical study, in which

Joanna Żukowska, Ph.D., assistant professor, Institute of International Management and Marketing, Warsaw School of Economics. Mikołaj Pindelski, Ph.D., assistant professor, Department of Management Theory, Warsaw School of Economics. 
large and medium businesses took part. Small and micro businesses are not subject to the empirical study due to the fact that the survey provided information that the data derived from is marginal and does not bring anything new to the study. Interviews were conducted by telephone or in person. The choice of form depended on preferences of company is being tested. However, the form of the study had no effect on the outcome. The telephone interviewers often received more detailed data than through the personal visits. The interview also received a form of an unstructured interview.

The study included 17 medium-sized and 23 large companies. However, due to the needs of this study, a mini-case study of medium-sized companies will be presented. Due to the fact that all of the companies that participated in the in-depth questionnaire based study reserved the confidentiality of names, only a description of the industry and a very concise description of the business were used, not allowing its subsequent identification by readers.

As a preliminary point, it should be noted that by analyzing the literature, we can draw a conclusion that the concept of training includes a number of various ways of enhancing competencies. Sometimes, you can even directly encounter the words - "the effectiveness of training and other forms of development" or "effectiveness of training and other forms increasing competence." Additionally, it can be concluded that the concept of training is widely recognized in the literature as a universal term, including direct training, workshops, courses, as well as coaching, mentoring, and graduate programs. Going one step further, it can be said that the tools measuring the effectiveness of training can refer to training within the direct and universal meaning. Thus, the validity of these tools will be applied to the measures of the effectiveness of all mentioned forms of increasing competence.

Moving on to the analysis of training effectiveness measures, let us concentrate on two most frequently used in the literature, recognized by the authors of the paper as the most relevant.

First, there is the Kirkpatrick model for the evaluation of training, which was first proposed in the late 1950s of the 20th century, much earlier than the development of the scientific interest in competence.

The model tests four levels of training, as shown in Figure 1.

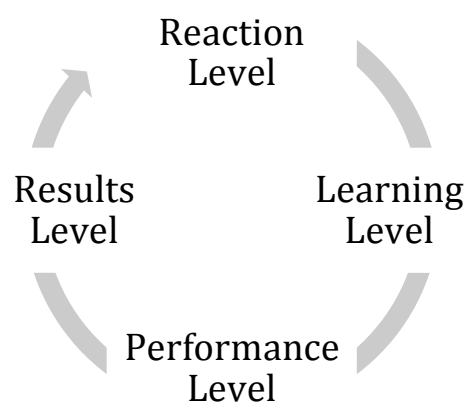

Figure 1. Four levels of effectiveness of training according to Kirkpatrick (1994).

It should be noted that the low rate obtained on one of the levels is not enough to evaluate the low efficiency of training. This means that it is absolutely necessary to examine all four levels, and draw conclusions based on results from each one of them.

The level of response should give an answer to the question "Whether the participants liked the training or not?" In order to verify the satisfaction, fulfillment, or knowledge of the information gained during the training, 
a survey or an in-depth interview with the participants of the training, is usually used. The very quality of the classes can be measured by an observation along with the use of checklists.

The second stage is the level of learning in which one should check whether the participants have acquired knowledge, skills, and changed attitudes. An effective tool here appears to be the measure of knowledge, using pre- and post- testing. At this point, we need to check if the level of knowledge and skills increased, and/or whether it is actively used at a workplace.

The third step examines if, on the behavioural level, participants daily apply skills acquired during the training, and if there is a flow of knowledge and experience.

At the final stage of results, it is verified if the training actually worked and increased the enterprise profits (Kirkpatrick, 1994). At this level, all managers who analyze the financial performance before and after training get engaged in the research. Helpful here can be the indicator of Return on Investment (ROI), investments and benefits sheets, or the cost-benefit analysis of a control group.

In reality, this is the most important, the most tangible element of measuring effectiveness, but at the same time, the most difficult one. This is due to the fact that during the study, other possible factors that could alter the profit should be taken into account (Mayo, 2002).

The second model is the Hamblin model, which is the extension of the Kirkpatrick model, by adding the fifth level, also called the level of ultimate value. They are related to the social and cultural values of the organization. In addition, Hamblin assumes that the key is to formulate the learning objectives before the training begins, allowing for the omission of this phase, if you encounter difficulties that prevent defining them (Woźniak \& Kozioł, 2012).

Both models seem to be very good and when used by organizations, allow us to obtain reliable data in a reasonable, in terms of firm commitment, manner. A certain disadvantage of the two methods (otherwise known as models) is, as a rule, the need to carry out all the steps. Only when the full the method is used, will it give the accurate and measurable results and information. But companies tend to use the first two stages of the methods, omitting the others (Żukowska, 2011).

In case of the Hamblin model, the last phase that refers to values and goals appears to be of a great value. However, both of the models have majority of advantages over the disadvantages, and even the indicated defect, from a scientific point of view, is not one. The principal advantages of these methods are inter alia, the clarity and transparency of the proposed steps, quite high intuitiveness of methods, a kind of simplicity, particularly in the initial stages, or financial ratios implementation as an additional factor, which gives a broader view of the range of the analyzed subject.

The training efficiency may also be tested by means of a multidirectional evaluation. It is based on auditing the following persons in the scope of training effects:

(a) The trainees;

(b) The trainers (Pocztowski, 2004);

(c) The training supervisors;

(d) The regular control of the results achieved (Szałkowski, 2002).

The method seems to be relatively simple to be applied. However, for some reasons unexplored so far, it is applied by businesses rather rarely. Furthermore, we may presume that even though businesses apply it, they do it subconsciously, not realizing that this is a scientific method of research. A certain deficiency of the method can be the risk related to the subjectivity of the evaluation, in case no appropriate comparison of the four areas 
has been carried out. The key advantage of the method, however, is definitely its simplicity and easiness of application by the business.

Another tool used for measuring the professional training efficiency is the C-I-P-O model that has been presented in Figure 2.

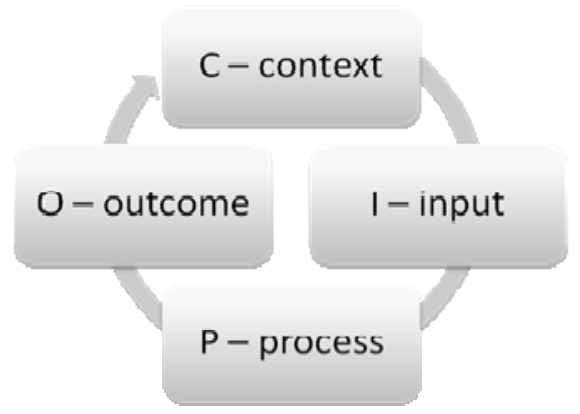

Figure 2. The C-I-P-O model.

"C" means context and is based on collecting and processing data on the organization's situation, its needs, difficulties, and issues, with particular stress put on the non-efficiency areas. "I" (Input) is the moment of collecting information that is to serve the choice of optimal training techniques and methods. "P" (process), is based on aggregation of the participants' opinions in the scope of the training itself and its course. The last stage is "O" (Outcome), comprising the training results analysis. The direct effects are noticeable after the training completion already and they refer to the changes in attitudes, behaviours, or knowledge. The indirect results are focused on the skills implementation effect in the workplace. The easiest way to test it is by means of a control group. The final long-term results concern the impact of the indirect results on the entire organization (Kunasz, 2006).

The control group testing is based on comparison of work efficiency on their posts of those who participated in the training to those who did not.

The exact control group testing procedure should be carried out according to the following steps:

1. Identifying measurable training needs and purposes of training itself;

2. Appointing two employee groups of which only one will participate in the training (Blömeke, Zlatkin-Troitschanskaia, Kuhn, \& Fege, 2011);

3. Carrying out a test on both groups prior to the training;

4. Defining the entire training costs (Armstrong, 2001);

5. Carrying out the training;

6. Testing both groups with the use of identical questionnaires, at defined time intervals;

7. Within 12 months from the training completion (Kuryłowicz-Rodoch, 1999);

8. Comparing the results of tests carried out in both groups;

9. Comparing the benefits gained by the employees who participated in the training to the costs thereof (Kunasz, 2008).

However, it is worth indicating that in as much the measure brings reliable results in so far it is time-consuming and engaging the organization. Therefore, it is very difficult to be applied and at the same time seems to be barely useful for the organization. The organizations do not usually want to lose their precious time 
for excessively developed analytic tools and, therefore, such measure seems to be of little benefit for the business.

However, it can be interesting for external researchers who would carry out tests in businesses. This is due to its specificity.

ROI, in case of training efficiency measure, is the definition of cause relationships taking place between the lack of knowledge or competence and negative events in the organization that need to be solved. It starts with the analysis of the training needs, the result whereof being the financial calculation of losses, in case of leaving an issue unsolved. Afterwards, the training is carried out and its efficiency is measured, verifying the financial expenses on training courses (Zgud \& Kossowska, 2000). It should be emphasized that the financial benefits are usually analyzed. However, in case of training courses, these are details that cannot be separated, therefore, they are non-measurable.

Another tool is the sheet of investments and benefits. The comparison of all the costs incurred on training to the entire measurable and non-measurable training effects is carried out with the use of such sheet. The non-measurable effects are weighted by monetary units and thus converted into measurable benefits. The data are aggregated both on the employee (individual) level and business (organizational) level (Kunasz, 2008).

All the financial measures are very interesting from the reporting point of view in the business. However, numerous data indicate that it is very difficult to measure such soft and intangible factors as competence by means of them (Weigel, Mulder, \& Collins, 2007). Therefore, in the authoress' opinion, they may only serve as a certain guideline helpful when using other training efficiency measures.

J. Phillips' model is also a measure worth attention. The evaluation offered by the training participants is used here. Their task is to determine the financial benefits given by training to the organization, including the identification of substantial improvements that can be implemented in the business after the training (Philips, Stone, \& Phillips, 2003). The test is carried out with the use of the set of questions presented in Figure 3.

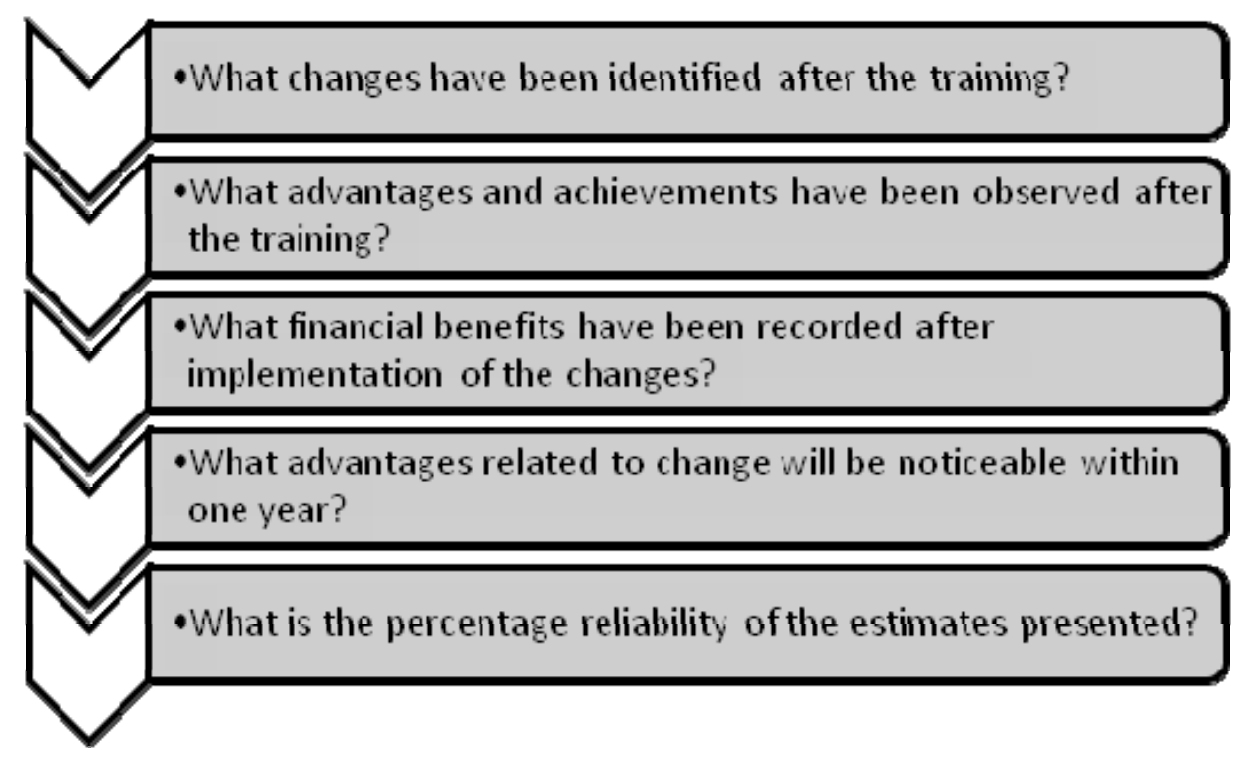

Figure 3. The set of questions used in J. Phillips' model.

Due to the estimate evaluations reported by training participants and the risk of their subjectivity, the model is often criticized. However, it is worth consideration as a method supplementary to another training efficiency evaluation method selected by the organization. 
Kawecka and Rogowska (2013) made a division of efficiency measures into two principal categories that they have defined as objective and descriptive methods. According to the authoresses, the objective methods use numeric scales, e.g., the number of telephone calls and meetings with the clients accomplished. The measure enables the percentage expression of the relationship of the exemplary condition to the one that actually occurs. It should also be remembered that the scales indicated do not have to prove efficiency at all. Nevertheless, the objective methods may prove right in case of repeatable, fairly standardized tasks. However, in case of some more complex tasks, more subjective, descriptive measures should be applied. They do not allow for expressing a measure simply in numeric categories. They constitute evaluating judgments, thus estimating the appearance of some behaviors or phenomena, as well as the intensity thereof.

An example of a measure frequently used for evaluation of employee workplace actions are Key Performance Indicators (KPI). KPI determine the extent of performance on a specific workplace, considering the foreseeable target achievement (Kawecka \& Rogowska, 2013). However, the measure is hardly related to the measures of competence improvement forms efficiency analyzed in this paper (also called indicators).

Analyzing the impact of competence on efficiency and the references, and basing on the interviews carried out in the businesses, we should pay attention to the fact that the management boards of the businesses declare that they are interested in the costs of competence as well as information concerning the importance of particular competences, assuring success to the organization.

However, both references and test results included in the further part of this paper indicate that it is often a declarative kind of information and not any actual verification. In this point, another research issue arises, which is worth analyzing at the next stage of research carried out by the authoress, i.e., design of universal competence models for selected sectors.

\section{Results and Discussion}

\section{Company-The IT Industry}

The company has been on the Polish market since 1987. It is one of the oldest existing private computer companies. The company specializes in the distribution of technology fields, such as storage systems, imaging systems, professional imaging systems, etc.. Apart from sales offers, the company also features consulting in the design of investment and provides comprehensive support for projects implemented solutions. Additionally, the company runs trainings for specific solutions or their functionality. Full service is also available. The company has several owners who fulfill management roles.

From the analysis of the manager's questionnaire, it shows that $45 \%$ of the employees have a college degree, while the remaining 55\% have a high school diploma. Despite the lack of commitment and employee satisfaction survey, along with the employee evaluation system, the company analyzes the training needs of employees, based on which they are assigned to various types of training courses. The company has specific job descriptions, yet there is no trace of written competence profiles. In the process of hiring new employees, the previous experience verified with former employers, the fit for the job descriptions, and the company's profile are all taken into account. Management prefers that the future employees are already adapted to their work position and there is no immediate need to improve their skills.

\section{Enterprise-The Manufacturing Industry}

The company was established in the 1990s as a branch of the Scandinavian company, famous for its 
production of emulsifiers and stabilizers used in the food industry. The enterprise is a manufacturer of high quality baking and confectionery blends with a well-developed distribution network, including tech-support for commercial and industrial manufacturers. The company also provides training for bakers, pastry chefs, and sales clerks. The enterprise is developing dynamically. Several owners manage and coordinate the firm.

The majority of the workforce have received high school education (65\%), 10\% have higher education, and only $25 \%$ of them have primary education. The company does not apply employee satisfaction surveys and there is no system for employee evaluation. There is also no analysis of training needs and no specific competencies profiles. Job descriptions are used during the recruitment process of new employees. Candidates are also screened in terms of experience, commitment, and hard work. Moreover, the management uses references from former employers.

Five percent of the employees were trained thanks to the European Union (EU) training courses, but only the individuals with the managing positions. This type of training was chosen due to the employee co-financing possibility. For the company, it "is financially beneficial." Due to the lack of the development performance testing or the job position effectiveness, we can generally state that the training courses had a great impact on such growth as well as the growth in the number of new customers.

\section{Enterprise-The Consulting Industry}

The company operates on the Polish market since 1997, but since 2007, it was noted down for a dynamic growth. The company is engaged in strategic human resources (HR) consulting and outsourcing services, such as payroll. Its headquarters are located in Warsaw, with a branch in some place in Poland, and coverage throughout the entire country. The company is run by executive branch that consists of a chief executive officer (CEO) and directors, who function as the management and the supervisors.

Data obtained from the executives show that $90 \%$ of the staff have a college degree and the remainder just have secondary education. The organization conducts employee commitment and satisfaction surveys. Additionally, there are employee assessment systems based on the $180^{\circ}$ method. Training needs analysis is performed, which, together with the employee assessment, sets the trend for further development of individual employees. There are also job descriptions with a hint of competency profiles. And when hiring new employees, there is mainly an emphasis on their enthusiasm and diligence, as the company recognizes that their competencies will develop right after hiring.

Last year, $25 \%$ of the employees participated in training and coaching programs. The company does use measures of the effectiveness of training (first two phases of Kirkpatrick), although there are no measures of job performance. An increase in the efficiency and sales of the firm along with attracting new customers is being observed, and all thanks to rising of qualifications of employees.

\section{Enterprise-The IT Industry}

The company was formed by the merger of two companies in the early 21 st century. The company is the publisher of video games for personal computers and video game consoles. It is managed and controlled only by a single CEO.

The questionnaire shows that $60 \%$ of the employees have higher education, and the remaining $40 \%$ are of the secondary education. The company does annual studies on the employee satisfaction and involvement. Furthermore, the training needs are analyzed through surveys and interviews. And the company has a mandatory system of employee evaluation. The findings are summarized and specific arrangements are introduced. The 
company has also specific job descriptions and competency profiles. Job descriptions are taken into account especially in the case of external recruitment process. Interestingly enough, during the staff recruitment process, less attention is paid to the current level of competence, bearing in mind the staff's further development.

The company organizes specialized trainings tailored to the business or employee needs. Twenty percent of the employees participated in such training sessions last year. It should be noted that the soft training was designed for managers and executives, and the hard training for the operational personnel and all others with such needs. Unfortunately, there is no measurement of the effectiveness of company trainings. Thus, generally speaking, the degree of development of employees has a subtle effect on the efficiency or customer growth.

\section{Enterprise-The Trade Industry}

Since 1999, the company has provided services in outsourcing, sales support, and business consulting, while maintaining the highest standards of quality and service. By using innovative procedures and extensive product offer, it is constantly adapting to the rapidly changing trends and mostly to the expectations and needs of the market. The company is managed by several directors.

In the company, $60 \%$ of the employees have a high school education diploma, $30 \%$ are college graduates, while only $10 \%$ have primary education. Once a year, there is a survey about employee commitment and satisfaction. Included are questions about the path of development, employee expectations, and level of commitment. The company examines the training needs based on which development programs are formed. There is a lack of employee evaluation system. The company has job descriptions and competence profiles for selected positions. They are taken into account during the recruitment process. The experience and communication skills of future employees are also examined. The management cares that the candidates perform efficiently when starting their new positions, without sacrificing the initial time on training.

The company's sales departments and operational staff undergo specialized and closed trainings. This method of developing employees' competences was chosen due to its specificity and, according to the management, larger benefits. According to the opinion of managers, trainings translate into increased efficiency of the company, and in part, to customer growth. Unfortunately, the absence of evaluating the effectiveness of forms of development and training, makes the information declared by the management intuitive.

\section{Enterprise-The Transportation Industry}

The company was established at the beginning of the 21 st century, and almost since the inception, it has been successful in the transportation industry. It has its own fleet and cooperates with domestic and foreign customers. The company is characterized by the unity of management and control powers.

The company has approximately 110 employees, of whom $60 \%$ have a college degree, while the remaining $40 \%$ have a high school diploma. The company does not conduct research on employee satisfaction. However, training needs are being analyzed. Moreover, there is a mandatory system for employee evaluation with the score based on the performance results and the supervisor's interview. The company has well-defined job descriptions and competency profiles. They are essential when recruiting new employees. Moreover, while considering the continued development of the candidates, less attention is paid to their actual competence.

The company declared that in regards to the development of employee competencies, particularly those holding senior positions, mentoring will be used. However, no one took any advantage of this particular form of development recently. Trainings translate into enhanced efficiency and number of new customers, but by the lack of using performance measures, this can only be an intuitive assessment. 


\section{Enterprise-The Pharmaceutical Industry}

In Poland, this particular copartnership is a part of one of Europe's largest pharmaceutical distribution companies. The company started creating its own chain of pharmacies since 2007 , and is managed by several directors.

Most of the employees (75\%) have a higher education degree, and the remaining $25 \%$ have a high school diploma. The company does not conduct research on employee commitment and satisfaction. There is no analysis of necessary training needs, or system for employee evaluation is not mandatory. The company has well-defined job descriptions and competency profiles. They are essential when recruiting new employees. According to the data provided by a manager, half of the company staff were recently subjected to the process of mentoring. The firm decided to work on increasing competences, because it permits the employee self-growth. Middle and upper level management, along with mid-level employees, were seconded to this form of increasing qualifications. Unfortunately, it contributed at a very low level to improving the efficiency of the company or to increasing in the number of customers. However, these data are only based on a statement, because the company has no records of the effectiveness of training.

\section{Enterprise- The Electromechanical Refrigeration Industry}

The company operates in the Mazovieckie Voivodship since the year 2000. It is a dealership distributing air-conditioning systems. It has been given competence certificate of category A in the business industry class. Regulations and subcontractors drafts of air-conditioning, heating, and ventilation are part of the company's offer. Additionally, it carries out maintenance, warranty, and post-warranty services. Its services cover the entire country. The enterprise belongs to a group of medium and private companies, with a $100 \%$ commitment to the Polish capital. The company has unity of power, and the executives act strictly as managers. The form of control is not significant, but in this case comprehensive.

Analyzing the personal aspect of the director's statement, it shows that as many as $40 \%$ of the staff have basic education, whereas $30 \%$ of employees have a high school and college degree. Such indicators can provide demand for further skills development. Therefore, the company carries out research about training needs. However, they are not linked to any other forms of HR strategic analysis, such as assessments of employee satisfaction or employee engagement surveys. In addition, the company has not identified competency profiles. But basic job descriptions do exist. Although competency profiles are not described, the recruitment process uses matching the employee to existing profiles and an intuitive feeling about the position of the expected competencies are both taken into account. It is important to the Management Board that the future employees already have a lot of experience and expertise (regardless of level of education) in order to effectively be able to start work on a given position. Furthermore, they must have willingness to grow and be creative.

Focusing only on methods that increase employee's competencies, the company often uses trainings in innovative manufacturing technology and the most actively trained group is the supervisors, which make up only $5 \%$ of the crew. Interestingly enough, according to the management, the most effective form of competence development is training and especially the ones from the EU, because "you can find the right training for employees at a reasonable price." Despite the modest level of participation in training, company officials see that these lead to an increase in the efficiency of the enterprise and the workers participating in training. Part of it has an impact on the growth performance of the company and increase the number of customers. Conclusions, however, are more intuitive and based on observation, because the company does not 
run any form of performance surveying development, including training, and there is no use of tools and gauges of their efficiency. Besides, measures of effectiveness of training or job positions are usually not being used.

\section{Enterprise-The Real Estate Industry}

The company was founded in 2001 in central Poland, and from the very beginning, it has been providing comprehensive real estate services in the region, the country, and abroad. The company offers specialized and professional services related to buying, selling, renting, leasing, and property appraisals. It also deals with financial intermediary supporting the opportunity of making real estate transactions. The unity of executive powers can be observed in this company. During testing, a person working as a manager estimated that $50 \%$ of employees have higher education, $44 \%$ have a high school diploma, and only $6 \%$ have primary education. The company does not have any employee evaluation systems, and does not apply employee satisfaction and commitment surveys. What is more, there is a lack of a training needs analysis. The company uses job descriptions. Unfortunately, they are not taken into account when recruiting new staff. The most important is experience. Competencies are less important, since their development is expected to start right after the hiring.

Only the senior management is subjected to training that allows further development of their competencies. Unfortunately, the company does not use performance measures for training and forms of development; therefore, we can only vaguely state that they have an impact on the number of clients and business performance growth. According to a respondent, qualified and competent staff can help to enhance the company's competitiveness.

\section{Enterprise-The Telematics Services Industry}

The company was founded in the year 2000, and it deals with tracking of vehicles through the use of telematics devices. It builds a strong market position based on its own platform localization, which is their own solution of combining advanced information system with location and data transfer technologies - Global Positioning System (GPS) and Global System for Mobile Communications (GSM). The company is characterized by the unity of management and control authorities.

Half of the company's employees have a high school diploma, and the remaining $50 \%$ have a higher education degree. The company does not have employee evaluation system, and does not apply employee satisfaction and commitment surveys. What is more, there is a lack of a training needs analysis or specific competence profiles. The company uses job descriptions, which are taken into account when recruiting new staff. Bearing in mind further development of newly hired staff, less attention is paid to the initial level of their competence.

Coaching is used with the company's executives, which in their opinion is being very effective. Thanks to these trainings, you can observe a significant increase in the efficiency of the company's results. Moreover, it shows in the growing number of clients. Unfortunately, due to the lack of performance measures, this information is only declarative.

\section{Enterprise-The Security Services Industry}

The company was launched in the market of physical and technical protection of individuals and property in 1992. The headquarters are located in Warsaw, with branches throughout the entire country. The company is managed and controlled by several owners. The largest percentage $(80 \%)$ of the people employed have a secondary education diploma, $15 \%$ are university graduates, and only $5 \%$ have a primary education diploma. 
All employees are subject to an annual study on engagement and employee satisfaction, which also includes (in a very restrictive form) elements of research training needs. They are the foundation for the employees' competence development. The company has not introduced an employee evaluation system. However, job descriptions do exist. When recruiting new staff, matching their competence to the job descriptions, their experience and skills are being considered. Interviewing the candidate's former employers is a frequent method of getting to know a person.

The company's entire staff undergo specialized and business training, through which they receive the necessary certificates. In previous years, these forms of development were subject only to $30 \%$ of the workforce. The managers claim that increasing the competence of the employees, contributes to, as much as half, the company's performance and efficiency growth. It also significantly contributes to the increased interest of new customers in the company's services. The HR department that aims to continuously improve the competence of companies and their monitoring is responsible for this task.

\section{Enterprise-The Construction Industry}

The company operates on the Polish market since the late 1990s. It has a fully domestic capital. It works in the construction industry, focusing on the construction of single-family homes and "Orlik" type school playgrounds. The company has one owner, who is also the manager.

More than half of the employees (54\%) in the company have a primary education diploma, $40 \%$ have a secondary one, and only $6 \%$ of the staff have a higher education diploma. The company does not perform any studies on involvement and employee satisfaction. Employee assessment or training needs analysis is not performed. Competency profiles have been replaced with job descriptions. Unfortunately, they are not used during the recruitment process of new employees. The experience, skills, and candidate's hard work are verified instead.

The company rarely conducts any training. And if any, mentoring, which continuously corrects mistakes and allows for faster development period, is chosen. The company does not measure the effectiveness of training, and therefore, the management only intuitively assesses that the development of employees only slightly translates into the company's growth performance or the number of new customers.

\section{Conclusion}

The companies sometimes use other forms of skills development, rather than traditional trainings. Coaching and mentoring are used in particular, but still, only occasionally.

It should be emphasized that the personnel policy is closely linked to better the competencies by the workers.

In most cases, the management is of the opinion that, during the recruitment process, it is better to choose a potential employee that does not require immediate competence development, but rather quickly, without any additional training, break him in.

The enterprises often carry job descriptions. According to the data, it can be assumed that job descriptions may not always be equivalent to the requirements of personnel management science, but rather to a list of responsibilities, which shall be annexed to the contract of employment. However, at this stage of the study, these are only assumptions, which should be deeply examined in the future.

The training needs research is most frequently used, and based on which, further solutions on competencies development are formed. 
The enterprises most frequently benefit from closed trainings which are tailored to each company, and most willingly are financed by the EU.

The obtained data also show that, on average, $5 \%-10 \%$ of staff are involved in training, with particular emphasis on management and sales staff.

The enterprises notice an increase in efficiency throughout the company thanks to solutions that raise competencies. In addition, they have a lesser but a positive effect on increased revenue and influx of new customers.

Based on management's statement, it often shows that the vast majority of companies do not conduct studies on the effectiveness of training and job performance, and the above observations are more intuitive than confirmed by the results of used measures. Managers are not able to indicate whether they apply methods of measuring the effectiveness of forms of raising competencies. Even if they think they do, they are not aware which methods they use. Moreover, they do not know about any methods of measuring the effectiveness of forms of skills development found in literature.

However, information from the interviews suggests that such measures are actually and frequently used, but the company is not aware that the tools used are actually measures of effectiveness. It should also be noted that the tools are usually consistent with those occurring in the first and sometimes the second stage of Kirkpatrick's model. No use of higher levels of the Kirkpatrick's model was observed. It should be emphasized that other methods have not been diagnosed at all. Also, the fifth stage of Hamblin's model does not occur.

Seldom do the managers believe that trainings have a minor impact on the effectiveness of job positions, the company, and revenue organization. They recognize the fact that trainings have a direct influence on a company's performance, but the data are based on their assumption. Usually, they read the information obtained literally. For example, if they know that their employees participated in trainings and simultaneously observe a profit growth, they recognize that these events are directly related to each other and one is a consequence of the other.

Furthermore, it is rare that they hire people with little experience or level of competence that still needs to be developed.

It is worth noting that managers often gave very modest opinions. You may think that it is primarily due to insufficient knowledge of the subject, which is the measurement of the effectiveness of forms of competencies development. Besides, their statements were focusing more on general personnel policy, rather than on measures of development analyzed in this study.

What is more, the opinions shared about the percentages of profit growth, the number of acquired customers, etc., seem to be significantly overestimated. According to the author, they are only an indication, since it is not a quantifiable data. They are based on the opinion of the respondents, and not on reliable financial data.

The paper goal has been the presentation of implementing efficiency measures of forms enhancing employees' competencies by middle-sized companies operating on the Polish market.

Summarizing the results of all the mini-case studies of medium-sized enterprises, it can be concluded that there are some differences in the approach to personnel policy, especially in the inter-company training policy. 


\section{References}

Armstrong, M. (2001). Handbook of human resource practice (8th ed.). London, U.K.: Kogan Page.

Blömeke, S., Zlatkin-Troitschanskaia, O., Kuhn, C., \& Fege, J. (2011). Modelling and measuring competencies in higher education: Tasks and challenges. Rotterdam: Sense Publishers.

Kawecka, M., \& Rogowska, A. (2013). Satysfakcja i zaangażowanie a efektywność pracowników: Wybrane uwarunkowania efektywności pracowników w organizacji (Satisfaction and commitment versus the employees' efficiency: Selected determinants of employees' efficiency in the organization). Retrieved from http://hpi.biz.pl/x.php/1,37/Determinanty-efekty wnosci.html

Kirkpatrick, D. L. (1994). Evaluating training programs. San Francisco, C.A.: Berrett-Koehler Publishers Inc..

Kunasz, M. (2008). Efektywność szkolenia $i$ doskonalenia zawodowego-Wybrane aspekty (Efficiency of training and professional improvement-Selected aspects). (Studies and Works of the Faculty of Economic Sciences and Management, No. 3, Uniwersytet Szczeciński.

Kunasz, M. (2006). Ocena efektywności szkolenia w przedsiębiorstwie w świetle wyników badań (Evaluation of training efficiency in a business, in view of research and testing results) (Materials and studies of the University of Warsaw).

Kuryłowicz-Rodoch, A. (1999). Inwestowanie w pracownika (Investing in the employee). Training Methods Review, Review and Social Security, 7-8.

Mayo, A. (2002). Ksztaltowanie strategii szkoleń i rozwoju pracowników (Formulation of the policy of personnel training and development). Kraków: Oficyna Ekonomiczna.

Philips, J. J., Stone, R. D., \& Phillips, P. P. (2003). Ocena efektywności w zarzqdzaniu zasobami ludzkimi (Evaluation of efficiency in the management of human resources) (Practical Manual of Measuring Profitability and Investment Projects). Kraków: Human Factor.

Pocztowski, A. (2004). Najlepsze praktyki zarzadzania zasobami ludzkimi w Polsce (The best practices of human resource management in Poland). Kraków: Oficyna Wydawnicza.

Szałkowski, A. (2002). Rozwój pracowników przestanki, cele, instrumenty (The development of employees—Prerequisites, targets, instruments). Kraków: Wydawnictwo AE Kraków.

Weigel, T., Mulder, M., \& Collins, K. (2007). The concept of competence in the development of vocational education and training in selected EU member states. Journal of Vocational Education and Training, 59(1), 53-66.

Woźniak, M., \& Kozioł, M. (2012). Kryteria i metody oceny efektywności szkoleń e-learningowych (The criteria and methods of evaluation of efficiency and e-learning courses). Zeszyty Naukowe Matopolskiej Wyższej Szkoły Ekonomicznej w Tarnowie, 21(2), 186.

Zgud, J., \& Kossowska, M. (2000). O ewaluacji raz jeszcze: Planowanie i projektowanie szkoleń pracowniczych (Once more about evaluation: Planning and designing personnel training). Personel, 3.

Żukowska, J. (2011). Wpływ szkoleń i innych form podnoszacych kwalifikacje pracowników na przedsiębiorstwo: Badania statutowe (The impact of training courses and other forms of improving personnel qualification on the business entity: Statutory studies). Warsaw: Warsaw School of Economics. 